\title{
Examining the Role of Attribution and Intercultural Competence in Intercultural Service Encounters
}

\begin{abstract}
With growing immigration, globalization and international tourism in recent years, there has been a rapid increase in intercultural service encounters. Yet, little is known about customers' satisfaction and their evaluations of these encounters. Customers' expectations, perceptions and evaluations of intercultural service encounters are likely to be different than those in intracultural service encounters wherein customers and employees share a common language, values and norms. This research aims to address this important knowledge gap by developing a model depicting the underlying customer satisfaction process in intercultural service encounters, and assess the hypothesized relationships in the model with real customers. The findings provide useful insights for managers to manage satisfaction of customers from diverse cultures.
\end{abstract}

Keywords: Customer satisfaction, intercultural service encounters, cultural attribution

This article has not been published elsewhere and that it has not been submitted simultaneously for publication elsewhere. 


\section{Examining the Role of Attribution and Intercultural Competence in Intercultural Service Encounters}

\section{INTRODUCTION}

Intercultural service encounters (ICSEs) involve interactions between customers and employees from different cultures (Stauss and Mang 1999). There has been a rapid increase in these encounters in recent years due to growing immigration, globalization and international tourism (United Nations 2010; World Tourism Organization 2012). There were almost 1 billion migrants worldwide in 2009 (International Organization for Migrants 2010), and about 980 million international tourist arrivals, and these tourists generated about US\$919 billion earnings in 2010 (World Tourism Organization 2012). In addition, the value of global trade in services was estimated at US\$7369 billions in 2011, accounting for about 11.65 percent of world GDP (World Bank 2012). All these suggest that intercultural service encounters are of increasing importance and prevalence.

Customer satisfaction occupies a central position in marketing thought and practice (Churchill and Surprenant 1982). The importance of customer satisfaction lies in its ability to influence post-purchase behavior. Satisfied customers are believed to make more repeat purchases and to share their positive experiences with others. On the other hand, dissatisfied customers may boycott the company, engage in negative word-of-mouth communications and or complain to a consumer organization (Tam 2008). The dyadic interaction between employee and customer during a service encounter is an important determinant of a customer's overall satisfaction with the service (Bianchi 2001). In intracultural service encounters where service employee and customer are from the same culture, employee and customer are more likely to 
have a common script and shared expectations about appropriate role behaviors, hence the likelihood of coordinated actions and satisfactory outcome are high (Solomon et al. 1985). But in intercultural service encounters, problems and misunderstandings are more likely to arise because employee and customer of diverse cultures may have different expectations and perceptions about each other's roles and behaviors.

There is scant research about customer satisfaction in intercultural service encounters. Prior research shows mixed findings regarding the relationship between perceived cultural distance and customer perceptions and evaluations (Etgar and Fuchs 2011; McKercher, Wong and Lau 2006; Stauss and Mang 1999). Thus, the objective of this research is to develop a model based on customer satisfaction and attribution theories together with a qualitative study to explain the underlying customer satisfaction process in intercultural service encounters, and empirically assess the hypothesized relationships in the model using a quasi-experiment with real customers. This research contributes to a better understanding of the underlying customer satisfaction process in intercultural service encounters, and offers useful insights for service managers to manage satisfaction of customers from diverse cultures.

\section{THEORETCIAL BACKGROUND}

\section{Perceived Cultural Distance}

Perceived cultural distance is the extent to which two cultures are perceived differently from each other and it is a result of differences in various cultural elements such as language, religion, social structure, and values (Triandis 1994). Weiermair (2000) suggests that cultural proximity and cultural distance are likely to influence customer satisfaction because of their different pre-conceptions and expectations. Customers show significant differences in their 
perceptions of service experiences with culturally different employees. For example, customers tend to prefer employees of the same race as themselves because of greater trust and familiarity, thus cross-race interactions result in more unfavorable outcomes than same-race interactions (Kulik and Holbrook 2000). Similarly, the perceived nationality of a service provider may be more important to customers than other factors, highlighting the effects of national stereotype on the selection of professional healthcare service providers (Harrison-Walker 1995) and a preference for domestic over foreign airlines (Bruning 1997). Studies show that customers tend to prefer destinations that are culturally close to their own culture (McKercher, Wong and Lau 2006; Ng, Lee and Soutar 2007). Etgar and Fuchs (2011) found that service provider similarity was positively related to service quality perception scores for Israeli Jewish respondents but not for Arab Israeli respondents.

However, Stauss and Mang (1999) did not find empirical support for the hypothesis that customer perceptions of intercultural encounters were more negative than of intracultural encounters. They explained that customers may attribute service failure to the cultural distance between them and the service employee on an ex post facto basis before making a judgment of satisfaction. Their findings seem to be in line with Warden et al. (2003) that service recovery strategies exhibit higher satisfaction ratings when experienced in a foreign cultural setting rather than a domestic setting. Pikkemaat and Weiermair (2001) also showed that tourists from very distant cultures yielded high quality scores than tourists from similar cultures. The lack of consensus on the influence of perceived cultural distance on customer satisfaction in intercultural service encounters highlights the complexity of the relationship between perceived cultural distance and customer satisfaction as well as the lack of a strong conceptual framework and 
methodological rigor for research in this area. The mixed findings suggest that some mediator and moderator variables may obscure the relationship.

\section{Attribution Theory}

Attribution is concerned with the ways in which people explain or attribute the behavior of others or the events they observe (Heider 1958). It has people attribute causes to events into two types: internal and external factors. Internal or "dispositional" attributions assign causality to factors within the person, e.g. effort or ability. External or "situational" attributions assign causality to environmental or situational factors, such as the weather or economic conditions. Weiner (1980) referred to this internal-external attribution as the locus of causality dimension. In this study, we are interested in examining the attribution process in an intercultural service encounter context. We define cultural attribution as assigning the cause of a service outcome being either satisfactory or unsatisfactory to the differences between a service employee and a customer in terms of language and culture.

Most of the attribution studies in marketing examined customers' reactions to product / service failure (Bitner 1990; Folkes 1984, Hartman, Meyer and Scribner 2009; Iglesias 2009; Weiner 2000). Attribution requires a motivating stimulus. Expected outcomes or successes may not generate an attribution process because they are, in most instances, foregone conclusions in the minds of consumers (Oliver 1997). But when unexpected outcomes or failures occur, customers would experience psychological discomfort and this would trigger them to look for the causes of the failures (Laufer 2002). Such activity is an attempt to restore their psychological equilibrium (Tse, Nicosia and Wilton 1990). Studies have shown that attribution influences 
subsequent satisfaction evaluations and behaviors (Bitner 1990; Choi and Mattila; 2008; Folkes 1984; Ha and Janda 2008; Iglesias 2009).

\section{Customer Satisfaction}

Customer satisfaction with a service encounter is an emotional state experienced in response to an evaluation of their service experience (Cadotte, Woodruff and Jenkins 1987; Oliver 1997). Expectancy-disconfirmation model has been used extensively in consumer satisfaction research to understand the customer satisfaction formation process (Oliver 1980). This model suggests that customer satisfaction is a function of expectations and the extent to which perceived service performance meets the expectations. If the perceived service performance exceeds expectations, positive disconfirmation occurs, which in turn determines the level of satisfaction. On the other hand, when the perceived service performance falls short of expectations, this leads to negative disconfirmation, and may result in dissatisfaction (Anderson and Sullivan 1993).

Zeithaml, Berry and Parasuraman (1993) introduced the concept of 'zone of tolerance', which is operationalized as the difference between desired and adequate service levels. Desired service level is the level of service that customers hope to receive, and adequate service level is a lower level of service than the desired service that the customer will accept. Inter-personal service encounters are heterogeneous in that performance may vary across providers, across employees from the same provider, and even within the same employee (Zeithaml, Bitner and Gremler 2009). Zone of tolerance is the extent to which customers recognize and are willing to accept this heterogeneity. Customers from different cultural backgrounds have significantly different expectations and their zone of tolerance may vary depending on their cultural 
background, cross-cultural knowledge, and or personal experience (Stauss and Mang 1999; Zeithaml, Bitner and Gremler 2009).

When a service performance falls below prior expectations, it may not directly lead to dissatisfaction, but it may result in customers being in a psychological disequilibrium state which may trigger them to engage in activities to restore the psychological equilibrium (Tse, Nicosia and Wilton 1990). Laufer (2002) suggests that customers would look for reasons to explain why their expectations are disconfirmed. This process results in what is known as attributions which have been shown to play an important role in determining customers' response to service failure (Folkes 1984; Hess 2008; Tsiros, Mittal and Ross 2004).

\section{QUALITATIVE STUDY}

To develop an understanding of customer experience and evaluations in intercultural service encounters, in-depth interviews were conducted with thirty customers with diverse cultural backgrounds and countries of origin (Hong Kong, Canada, Korea, India, the United Kingdom, the United States). The findings of the interviews will be used as inputs for hypothesis development. Interview guides were developed in English first, then translated into Chinese and back-translated into English. Three well-trained researchers conducted the in-depth interviews. One of the researchers, a local Chinese, conducted the interviews in Chinese whereas the other two researchers conducted the interviews in English. In the interviews, respondents were asked about their experience and satisfaction with intercultural service encounters, and what challenges or difficulties they face when dealing with service employees from other cultures. Then, they were asked whether they perceive any differences in their experience and perceptions when compared with intracultural service encounters. They were also asked whether they had 
encountered an unsatisfactory intercultural service encounter, and if so, to elaborate how and why this encounter had happened. The interviews lasted from 35 to 90 minutes and were recorded and transcribed.

The researchers reviewed the transcripts independently, then shared and discussed their inferences in detail over several meetings. "Triangulation across researchers" is a wellestablished practice to analyze qualitative data in marketing (Belk, Sherry and Wallendorf 1988; Sharma, Tam and Kim 2009; Zeithaml, Berry and Parasuraman 1993). Using this approach, we were able to identify some common patterns and some differences in responses among the participants in the in-depth interviews. The most frequently mentioned challenges in intercultural service encounters are language barriers and differences in expectations between customers and employees. The following are some examples of the responses given by the participants:

"Language barriers are definitely the most challenging. Sometimes when service employees realize there is a language barrier, they can become much less helpful as they would rather not bother serving you, as it is more hassle from them.”

"Communication and differences in expectations. The language barrier is an issue. Also, there are differences in expectations, norms and behaviors between me and the employees."

“The service employees just do not understand why you would want to prepare food in a different way than they would usually prepare it, e.g., a vegetarian option in a country where there is almost no concept of vegetarianism."

"They (the employees) have an agenda. I mean the ways of doing things are different from those in my home country. They are doing things according to their own script."

Although participants considered language barriers and discrepant expectations between customers and employees the challenging issues in intercultural service encounters, it is noted 
that participants who are more aware of other cultures and have more experience of intercultural encounters perceive and evaluate intercultural service encounters differently than those who are less aware and have less experience. They feel more confident and more in control in intercultural service encounters, and are willing to adapt and adjust their behaviors to other cultures. When service failures or problems arise, they discount the cultural differences between customers and employees as the source of the outcome. The following example statements are made by who participants who have frequent experiences of intercultural encounters.

A hotel manager aged about 40, born and raised in Hong Kong. He has been working in the hospitality industry for more than 15 years and has travelled to many different places: "I am more open and patient when dealing with a service employee from other cultures. I know that there are cultural differences between us (i.e., me and the employee), but I am willing to adapt and adjust my behaviors. When failure occurs during an intercultural service encounter, I think it is more likely due to the quality of the employee rather than the cultural differences between me and the employee."

A graduate trainee aged about 25, born and raised in Canada. She has visited many places including Hong Kong, Japan, U.S., Europe and China. She had been given an opportunity to study one semester in China: "I normally get on fine with people from other cultures. It depends on the individual. I had an unsatisfactory experience in a local restaurant in Shanghai. I was ordering a dish and asked for no chicken in the dish. However, the waitress didn't understand what I was saying. I thought I was decent at Putonghua. I was sharing the table with a Shanghainese stranger, and he certainly understood what I was saying. When he told the waitress the seemingly exact same thing I was telling her, she refused to listen to the man and pretended 
still not to understand. I think the waitress was incompetent rather than this being a cultural misunderstanding."

Compared to the participants who had less experience of intercultural encounters, cultural factors such as language barriers and cultural differences seem to be the common underlying source of an unsatisfactory outcome. Although the participants were unhappy about the service, they think that the source of the problem was cultural differences rather than service personnel as reflected in the following examples.

A sales assistant in her late 20s, born and raised in Hong Kong. She had had holidays once every two years in the past eight years. She travelled with a tour each time, and she did not need to communicate with the local people as there was a tour guide and a local tour guide who could speak her own language: "Unsatisfactory encounters mostly occurred in restaurants in China. The service there was very slow. I think it was due to the cultural differences between Hong Kong and the Mainland China. In Hong Kong, we were used to fast service. I would lower my expectations if I were receiving services outside Hong Kong. I did not want to make a fuss as I was only there for a holiday."

A clerk in his early 30s, born and raised in Hong Kong. He had only had experiences of intercultural service encounters when he was on holidays. Most of his holidays were spent in China but he had visited several countries in Southeast Asia. He recalled an unsatisfactory service encounter in a hotel in Japan: "We could not switch on the lights in our hotel room, so we sought assistance from the hotel staff. There were communication problems. The staff understood very little English. When the staff member realized what the problem was, he took a very long time to fix it. We thought that he could fix the problem sooner. This shows a problem 
of communication and of cultural differences. In Hong Kong, if we had encountered a similar problem, we could have had it fixed much quicker."

To summarize, the qualitative study provided some preliminary insights into customers' evaluations and responses to intercultural service encounters. In the next section, we develop the hypotheses based on the review of the literature and the inputs from the in-depth interviews.

\section{HYPOTHESES}

\section{Relationship Between Perceived Cultural Distance and Customer Satisfaction}

Hartman, Meyer and Scribner (2009) consider that cultural distance can serve as a cushion such that it will mitigate the influence of intercultural aspects of experience on customers' perceptions and evaluations. Reichert and Gill (2004) argue that when there is little cultural distance, customers may feel that service provider should know their standards and therefore feel that the service provider should provide service accordingly. However, with a large cultural distance, customers have a wider zone of tolerance because they do not have clear and firm expectations about the service outcome as they are not familiar with the service and or the customs (Hartman, Meyer and Scribner, 2009; Stauss and Mang 1999; Tam 2007; Weiermair and Fuchs 2000). The results of our qualitative study support this argument. One of the respondents said: "I expect that local employees will understand my needs and expectations as we share a common language and cultural backgrounds. Hence, my expectations of the service by local employees are higher than of employees of different cultures". A second respondent said: "I lower my expectations and become more tolerant when I interact with an employee from a different cultural background due to differences in our languages and uncertainty in the outcomes." Hence, we propose that: 
$\mathrm{H}_{1}$ : There is a positive relationship between perceived cultural distance (PCD) and customer satisfaction (SAT).

\section{The Mediating Role of Attribution in Satisfaction Evaluation}

Attribution involves cognitive processes through individuals inferring the cause of the behavior of others or the events they observe (Calder and Burnkrant 1977). It plays an important role in determining customers' response to product / service failure (Folkes 1984). When service problems or failures arise, customers are motivated to search for the causes of the problems / failures. Depending on the perceived nature of the causes, their level of dis/satisfaction may be modified (Bitner 1990; Laufer 2002). In an intercultural service encounter context, we expect that the larger the cultural distance between employee and customer, the more likely the customer will attribute the causes of the problems / failures to cultural differences because these are easily noticeable factors (Hartman, Meyer and Scribner 2009), and this in turn will influence customer satisfaction. In other words, when failures occur in intercultural service encounters, we expect that the effect of perceived cultural distance on customer satisfaction will be mediated by cultural attributions. Positioning attribution prior to customer satisfaction is consistent with the literature (Bitner 1990; Hess 2008; Iglesias 2009; Tsiros, Mittal and Ross 2004; VàzquezCasielles et al. 2007). Thus, this leads to: $\mathrm{H}_{2}$ : Cultural attribution (CA) mediates the relationship between perceived cultural distance (PCD) and customer satisfaction (SAT).

\section{The Moderating Role of Intercultural Competence in Satisfaction Evaluation}


Intercultural competence (ICC) is the ability to think and act in appropriate ways with people from other cultures (Friedman and Antal, 2005). It plays an important role in achieving customer satisfaction in intercultural service encounters (Pikkemaat and Weiermair 2001). According to Triandis (2006), culturally intelligent people suspend judgment in an intercultural interaction until they have more information beyond the ethnicity of the others. They are also more aware of the nuances of different cultures and use this knowledge to adjust their own behavior. Hence, people with high ICC may be more open to learn about other cultures and willing to comply with social norms (Earley, Murnieks and Mosakowski 2007). This is consistent with our findings in the qualitative study. People with high ICC consider that ability to adapt and adjust their behaviors to other cultures is an important factor in intercultural service encounters. A female business executive who has a lot of experience in intercultural encounters said: "Cultural difference is not the key issue. We are aware of the cultural differences prior to consumption, and we know these differences cannot be changed. Personnel quality is important. What it matters is that employees and customers can adapt and accommodate their behaviors to each other."

In contrast, people with low ICC have little knowledge about other cultures and are less proficient in other languages, therefore language and cultural differences are not only the major barriers but also the most salient in intercultural service encounters (Hartman, Meyer and Scribner 2009). The in-depth interviews showed that when there are failures or problems arise in an intercultural service encounter, people with low ICC tend to attribute these failures or problems to cultural differences. However, people with high ICC not only feel more in control in an unfamiliar environment, but they are also able to predict what others will do and can act so as to get others to do what they want (Triandis 1994). Hence, we expect that low ICC people are 
more likely to attribute service failures to external (or situational) rather than internal (or individual) factors, and this in turn will influence customer satisfaction. In other words, we expect that the moderating effect of intercultural competence on the relationship between perceived cultural distance and customer satisfaction will be mediated by cultural attribution. Hence, we propose that: $\mathrm{H}_{3}$ : Cultural attribution (CA) mediates the moderating effect of intercultural competence (ICC) and perceived cultural distance (PCD) on customer satisfaction (SAT).

People with high ICC display more respect and empathy for people from other cultures (Lustig and Koester 2006). They can tolerate ambiguity and react to new and ambiguous situations with greater comfort than people with low ICC (Dodd 1998). Sharma, Tam and Kim (2009) posit that high ICC people may not only be aware of cross-cultural differences in roles and expectations, but they are also more likely to agree with these differences. Hence, we expect that for people with high ICC, a high cultural attribution may lead to high customer satisfaction compared to those with low ICC because they have high acceptance of other cultures and are more open and tolerant towards other cultures. This leads to our fourth hypothesis:

$\mathrm{H}_{4}$ : The mediated relationship of perceived cultural distance (PCD) on customer satisfaction (SAT) via cultural attribution will be moderated by intercultural competence such that the relationship between cultural attribution and customer satisfaction will be stronger for high intercultural competence (ICC) than low intercultural competence (ICC).

$<$ Insert Figure 1 about here $>$

\section{METHOD}

\section{Sample and Procedure}


A structured questionnaire was used to elicit responses to an imaginary service failure scenario in an intercultural service encounter, using a restaurant setting similar to those used in prior research (e.g., Smith and Bolton 1998; Smith, Bolton and Wagner 1999). We first showed a picture of a waiter to the participants to prime the low vs. high perceived cultural distance condition, using two sets of pictures in a randomized order, a Westerner vs. a Chinese waiter, which were chosen based on a pretest. Next, the participants read a service failure scenario and imagined themselves in that situation as a customer (same as their role in real life). The scenario described the participant as going to a fine dining restaurant but had to wait a long time for service and received the wrong food. Slow service and wrong orders are commonplace in the restaurant industry (Hess 2008; Patterson and Mattila 2008). Finally, the participants responded to scales measuring PCD, ICC, CA and SAT, followed by demographic questions including age, gender, education and occupation. The scenario is presented in the appendix.

The use of such a quasi-experimentation approach is quite common in consumer research and it can enhance internal validity by increasing control over the manipulated variables and reducing the influence of extraneous variables (Cook and Campbell 1979). However, the imaginary scenarios and experimental setting may limit the external validity of this approach. We overcome these limitations by using real customers, and a realistic dining experience describing a service encounter of between a customer and an employee. We also show pictures of a restaurant and an employee to the participants, to make it easier for them to imagine themselves in the situation described in the scenario and determine their reactions to the situations. These steps give our study a reasonable degree of experimental and mundane realism (Bitner 1990). 
A team of trained undergraduate students recruited customer participants using a mallintercept approach in Hong Kong. We restricted the study to local Chinese customers. While this may limit the generalizability of our findings, it helps to test our hypotheses in a more rigorous manner by controlling other extraneous cultural factors that may have influenced our findings. We contacted about 2,000 adult shoppers and collected 245 questionnaires (response rate $=12 \%$ ). After removing nine questionnaires with missing data, the final sample used for analysis was 236 . The sample comprised $46.6 \%$ males and $53.4 \%$ females. Nearly $42 \%$ of the respondents were aged $21-30$, and about $77 \%$ were singles and $23 \%$ were married.

\section{Measures}

The measures used in this study were mostly adapted to our context of a service failure in an intercultural service encounter in a restaurant setting from well-established scales as follows:

- Perceived cultural distance: Five items were adapted from the cultural distance scale $(\mathrm{Ng}$, Lee and Soutar 2007), with a seven-point Likert format.

- Intercultural competence: Ten items were adapted from a cultural intelligence scale (Ang et al., 2007) and an intercultural sensitivity scale (Hammer, Bennett and Wiseman 2003), using a seven-point Likert format.

- Cultural attribution: Three items were developed to measure cultural attribution in terms of differences in culture and language

- Customer satisfaction: Three items were adapted from existing customer satisfaction scales (e.g., Brady et al. 2005; Tam 2005), using a seven-point Semantic Differential format.

Exploratory factor analysis with varimax rotation was first performed. The results show a clear rotated five factor-loading structure, accounting for $80 \%$ of the total variance. Ten items of 
intercultural competence were loaded on two factors and the other items were loaded on their respective factors. Hence, an aggregate measure of each of the two dimensions of intercultural competence was computed by averaging its respective items, and they represented the indicators of intercultural competence. The reliability and structures of the scales were further assessed using confirmatory factor analysis via LISREL8. The measurement model shows a good fit $\left(\chi^{2}=164.72, \mathrm{df}=59, \mathrm{RMSEA}=0.087, \mathrm{GFI}=0.90, \mathrm{NFI}=0.93, \mathrm{CFI}=0.96\right)$. All factor loadings are higher than 0.60 and t-values are significant $(p<0.01)$. Table 1 shows the psychometric properties of the scales.

$<$ Insert Table 1 about here $>$

A closer look at the output shows that all the parameter estimates $(\lambda s)$ are significantly different from zero at the 5\% level, suggesting a high degree of convergent validity; and none of the confidence intervals of the correlation coefficients for each pair of scales ( $\Phi$ estimates) includes 1.0, thus supporting the discriminant validity of the scales (Anderson and Gerbing 1988). For an additional test of discriminant validity we constrained the estimated correlation parameters among all four factors to 1.0 and found that the $\chi^{2}$ value for this constrained model was significantly higher than the unconstrained model. Hence, none of the factors are perfectly correlated (Anderson and Gerbing 1988). Finally, the construct reliabilites ranged from 0.71 to 0.93, and the average variance extracted (AVE) ranged from 0.57 to 0.81 for all the scales. Hence, all scales are deemed reliable (Bagozzi and Yi 1988).

\section{ANALYSIS AND RESULTS}

\section{Manipulation Check}


An independent sample t-test was performed with as perceived cultural distance as the test variable. The results show that participants exposed to the picture of a Western waiter reported a high perceived cultural distance (mean=3.87) unlike those exposed to the picture of a Chinese waiter $($ mean $=3.01 ; \mathrm{t}=4.11, \mathrm{p}<0.00)$. Hence, our manipulation was effective.

\section{Hypotheses Tests}

To assess $\mathrm{H}_{1}$, we regressed the effect of perceived cultural distance on customer satisfaction and found that perceived cultural distance exerted a significant positive effect on customer satisfaction $(\beta=0.103$, $\mathrm{p}=0.008)$, thus $\mathrm{H}_{1}$ was supported. We next assessed $\mathrm{H}_{2}$, by following the mediation analysis recommended by Baron and Kenny (1986). It was found that perceived cultural distance was positively related to customer satisfaction, and cultural attribution was also positively related to customer satisfaction at the 5\% significance level. The effect of perceived cultural distance on customer satisfaction became insignificant after controlling for the effect of cultural attribution at the 5\% significance level (Sobel's $Z=2.46$, $\mathrm{p}=0.01)$. The results show that cultural attribution fully mediated the relationship between perceived cultural distance and customer satisfaction, thus $\mathrm{H}_{2}$ was supported.

We followed the analysis recommended by Muller, Judd and Yzerbyt (2005) to assess $\mathrm{H}_{3}$. To demonstrate mediated moderation, there should be an overall moderation of the intercultural competence effect on customer satisfaction, that is $\left(\beta_{13} \neq 0\right)$. If it does, the moderation of the residual direct effect $\left(\beta_{33}\right)$ of perceived cultural distance should be reduced in magnitude or become insignificant in the case of fully mediated moderation compared to the moderation of the overall perceived cultural distance effect $\left(\beta_{13}\right)$.

The results of Model 1 show that the coefficient for the product of perceived cultural distance and intercultural competence was significant at the 5\% significance level and indicated 
an overall moderating effect of intercultural competence $\left(\beta_{13}=-0.086, \mathrm{p}=0.004\right)$. The first condition is supported. We are interested in whether the mediating process accounted for this moderation effect. The results of Model 2 show that the effect of perceived cultural distance on cultural attribution was significant $\left(\beta_{21}=0.649, \mathrm{p}=0.001\right)$ and this effect was moderated by intercultural competence $\left(\beta_{23}=-0.09, \mathrm{p}=0.035\right)$. The results of Model 3 reveal that once we controlled for the cultural attribution and its interaction with intercultural competence, and allowed the indirect effect via cultural attribution to be moderated, the moderation of the residual direct effect of perceived cultural distance declined in magnitude compared to the moderation of the overall effect of perceived cultural distance $\left(\beta_{33}=-0.056\right.$ vs $\left.\beta_{13}=-0.086\right)$. There is evidence to support a partially mediated moderation of intercultural competence on the relationship between perceived cultural distance and customer satisfaction via cultural attribution, hence $\mathrm{H}_{3}$ was supported. From the results of Model 3, we also observed that the coefficient for the product of cultural attribution and intercultural competence was insignificant $\left(\mathrm{b}_{35}=-0.048, \mathrm{p}=0.223\right)$. There is no evidence to support that intercultural competence moderates the mediated relationship of culture attribution on customer satisfaction, hence $\mathrm{H}_{4}$ was not supported. Table 2 displays the results of the analysis.

$<$ Insert Table 2 about here $>$

\section{DISCUSSION AND IMPLICATIONS}

Overall, we found support for all hypotheses except one and our findings extend the existing research on the important topic of intercultural service encounters, with several conceptual contributions and managerial implications. First, as hypothesized we found that perceived cultural distance is positively related to customer satisfaction, and cultural attribution plays an important role in mediating the relationship between these two variables. Although one may 
expect that a lower perceived cultural distance between customers and employees may facilitate their communication with each other and improve the quality of their interaction and its outcomes. The findings of our in-depth interviews and empirical analysis suggest that customers seem to become more tolerant and lower their expectations when they interact with employees from different cultures due to high uncertainty of the outcome. Hence, given the same service failure, customers may feel less dissatisfied with the service provided by an employee of a different culture than with the service provided by an employee of the same culture. We have also shown that attribution to cultural differences (in terms of language, customs etc) mediates the relationship of perceived cultural distance on customer satisfaction. Hence, this seems to be in accord with Hartman, Meyer and Scribner (2009) that cultural differences may serve as a cushion which mitigates unpleasant experience in an intercultural service encounter failure.

Second, our study introduced the importance of intercultural competence in customer satisfaction evaluation. Specifically, we show that cultural attribution mediates the moderating effect of intercultural competence and perceived cultural distance on customer satisfaction. Customers with high intercultural competence seem to associate perceived cultural distance with cultural attribution for a service failure to a lesser extent compared to those with low intercultural competence, which is consistent with the findings of our in-depth interviews. However, there is no evidence to support the contention that customers with high intercultural competence associate cultural attribution more positively with customer satisfaction compared to customers with low intercultural competence. In other words, both high and low intercultural competence customers seem to be tolerant in their evaluations in an intercultural service encounter failure.

Intercultural service encounters are a complex socio-cultural phenomenon. They involve interactions between employees and customers from different cultural backgrounds. Our research 
shows that not all customers are the same; some have higher intercultural competence than others and this may influence their attribution process and subsequent customer satisfaction evaluation. It is important for service firms to train their employees to be sensitive to cross-cultural differences in customer expectations as well as differences in intercultural competence among diverse multi-cultural customers and to take these into account when serving them. Our findings also show that cultural attribution plays an important role in satisfaction evaluation in intercultural service encounters. Service firms may need to educate their customers from diverse cultures about local norms and practices, and proactively manage their expectations throughout the service experience such that customers feel that perceived poor service performance if encountered may be due to cultural differences rather than incompetent or unhelpful employees.

\section{LIMITATIONS AND FUTURE RESEARCH}

This research contributes to the marketing literature by advancing our theoretical knowledge and empirical evidence regarding the role of cultural attribution and intercultural competence in intercultural service encounters. Yet, it has several limitations that need to be noted. First, although we control for various extraneous variables by using a field experiment approach with local customers in Hong Kong, these may restrict the generalizability of our findings, and hence, future research should assess the framework with customers from diverse cultures. Moreover, future research may include scenarios in a different service setting as well as with alternative outcomes such as successful and normal service delivery to assess the generalizability of our findings.

We adapted scales that were originally developed in the Western countries and in view of the significant cross-cultural differences in customer expectations, perceptions and evaluations (Zhang, Beatty, and Walsh 2008), it is not clear if these scales help us to capture constructs that 
have similar meanings across different cultures. Hence, future research may need to establish the cross-cultural measurement equivalence of these scales before using them in other cultures.

Lastly, this research focuses on cultural attribution in intercultural service encounters. It is acknowledged that there are other attribution dimensions such as stability and controllability which may interact with perceived cultural distance and influence subsequent customer satisfaction evaluation. Future research should consider these various dimensions and examine their mediating role on the moderating effect of perceived cultural distance and intercultural competence on customer satisfaction to advance a complete understanding of the psychological process underlying customer satisfaction in intercultural service encounters.

\section{Appendix I}

\section{Intercultural Service Encounter Scenario}

"You go to a fine-dining restaurant for dinner. First you have to find a table yourself and then wait for 15 minutes before the waiter comes to your table. He seems to be in a hurry and does not even greet you properly. He throws the menu down on the table and walks away. You decide on your order but have to wait for another 15 minutes before the waiter comes back to take the order. After he walks away with the order, you have to wait for almost 30 minutes before he comes back with the food. You are shocked to find that you did not get what you had ordered. When you point this out to him, he does not apologize, simply shrugs his shoulders and walks away." 


\section{References}

Anderson. J. C. and Gerbing, D. W. 1988. Structural equation modeling in practice: a review and recommended two step approach. Psychological Bulletin 103 (May): 411-423.

Anderson E. and Sullivan M. 1993. The antecedents and consequences of customer satisfaction for firms. Marketing Science 12: 125-43.

Ang, S., Dyne, L., Koh, C., Ng. K. Y., Templer, K., Tay, C. and Chandrasekar, N. A. 2007. Cultural intelligence; its measurement and effects on cultural judgment and decision making, cultural adaptation and task performance. Management and Organization Review 3(3): 335-371.

Bagozzi, R. and Youjae, Y. 1988. On the evaluation of structural equation models. Journal of The Academy of Marketing Science 16(1): 74-84.

Baron, R. M. and Kenny, D. A. 1986. The moderator-mediatior variable distinction in social psychological research: conceptual, strategic, and statistical considerations. Journal of Personality and Social Psychology 51: 1173-1182.

Belk, R., Sherry, J. and Wallendorf, M. 1988. A naturalistic inquiry into buyer and seller behavior at a swap meet. Journal of Consumer Research 14 (March): 449-470.

Bianchi, C. 2001. The effect of cultural differences on service encounter satisfaction. AMA Winter Educator's Conference, Scottsdale, Arizona.

Bitner, Mary Jo 1990. Evaluating service encounters: the effects of physical surroundings and employee responses. Journal of Marketing 54 (April): 69-82. 
Brady, M., Knight, G., Cronin, J. Jr., Hunt, T. and Keillor, B. 2005. Removing the contextual lens: a multinational multi-setting comparison of service evaluation models. Journal of Retailing 81(3): 215-230.

Bruning, E. R. 1997. Country of origin, national loyalty and product choice: the case of international air travel. International Marketing Review 14(1): 59-74.

Cadotte E., Woodruff R. and Jenkins R. 1987. Expectations and norms in models of consumer satisfaction. Journal of Marketing Research 24(August): 305-14.

Calder, B. and Burnkrant, R. 1977. Interpersonal influence on consumer behavior: an attribution theory approach. Journal of Consumer Research 4: 29-38.

Choi, S. and Mattila, A. 2008. Perceived controllability and service expectations: influences on customer reactions following service failure. Journal of Business Research 61: 24-30.

Cook, T. C. and Campell, D. T. 1979, Quasi-experimentation: design and analysis issues for field settings. Chicago: Rand McNally, Inc.

Churchill G. A. and Surprenant C. 1982. An investigation into the determinants of customer satisfaction. Journal of Marketing Research 19 (November): 491-504.

Earley, P., Murnieks, C. and Mosakowski, E. 2007. Cultural intelligence and the global mindset. Advances in International Management 19:75-103.

Etgar, M. and Fuchs, G. 2011. Does ethic/cultural dissimilarity affect perceptions of service quality. Services Marketing Quarterly 32: 113-128. 
Folkes, V. S. 1984. Consumer reactions to product failure: An attributional approach. Journal of Consumer Research 10 (March): 398-409.

Friedman, Victor J. and Antal, A. B. 2005. Negotiating reality: a theory of action approach to intercultural competence. Management Learning 36(1): 69-86.

Ha, H. Y. and Janda, S. 2008. An empirical test of a proposed customer satisfaction model in eservices. The Journal of Services Marketing 22(5): 399-408.

Hammer, M., Bennett, M. and Wiseman, R. 2003. Measuring intercultural sensitivity: the intercultural development inventory. International Journal of Intercultural Relations 27: 421443.

Harrison-Walker, L. J. 1995. The relative effects of national stereotype and advertising information on the selection of a service provider: an empirical study. The Journal of Services Marketing 9(1): 47-59.

Hartman, K. B., Meyer, T. and Scribner, L. 2009. Retail and service encounters: the intercultural tourist experience. Journal of Hospitality Marketing and Management 18:197-215.

Heider, F. 1958. The psychology of interpersonal relations. New York: Wiley.

Hess, R. Jr. 2008. The impact of firm reputation and failure severity on customers' responses to service failures. Journal of Services Marketing 22(5): 385-398.

Iglesias, V. 2009. The attribution of service failures: effects on consumer satisfaction. The Service Industries Journal 29(2): 127-141. 
Jöreskog K. G. and Sörbom D. 1993. LISREL 8: structural equation modeling with the SIMPLIS command language. Scientific Software International, Inc.

Kulik, C. T. and Holbrook, R. L. 2000. Demographics in service encounters: effects of racial and gender congruence on perceived fairness. Social Justice Research 13(4): 375-402.

Laufer, D. 2002. Are antecedents of consumer dissatisfaction and consumer attributions for product failures universal? Advances in Consumer Research 29: 312-317.

Lustig, M. and Koester, J. 2006. Intercultural competence: interpersonal communication across cultures. Boston, MA: Pearson.

McKercher, B., Wong, C. and Lau, G. 2006. How tourists consume a destination. Journal of Business Research 59(5): 647-52.

Muller, D., Judd, C. M. and Yzerbyt, V. Y. 2005. When moderation is mediated and mediation is moderated. Journal of Personality and Social Psychology 89(6): 852-863.

Ng, S. I., Lee, J. A. and Soutar, G. N. 2007. Tourists' intention to visit a country: the impact of cultural distance. Tourism Management 28(6): 1497-506.

Oliver, R. 1980. A cognitive model f the antecedents and consequences of satisfaction decisions. Journal of Marketing Research 17 (November): 460-469.

Oliver, R. 1997. Satisfaction: a behavioral perspective on the consumer. McGraw-Hill.

Patterson, P and Mattila, A. 2008. An examination of the impact of cultural orientation and familiarity in service encounter evaluations. International Journal of Service Industry Management 19(5): 662-681. 
Pikkemaat, B. and Weiermair, K. 2001. The importance of cultural distance in the perception of evaluation of service quality. Journal of Quality Assurance and Hospitality and Tourism 2(1/2): 69-87.

Reichert, C. and Gill T. 2004. Effect of cultural distance on customer service satisfaction: a theoretical framework and research agenda. Advances in Consumer Research 31: 202-207.

Sharma, P., Tam, J. L. M. and Kim, N. 2009. Demystifying intercultural service encounters: toward a comprehensive conceptual framework. Journal of Service Research 12(2): 227-242.

Smith, A. and Bolton, R. 1998. An experimental investigation of customer reactions to service failure and recovery encounters. Journal of Service Research 1(1): 65-81.

Smith, A., Bolton, R. and Wagner, J. 1999. A model of customer satisfaction with service encounters involving failure and recovery. Journal of Marketing Research XXXVI (August): $356-372$

Solomon, M. Surprenant, C., Czepiel, J. and Gutman, E. 1985. A role theory perspective on dyadic interactions: the service encounter. Journal of Marketing 49 (1): 99-111.

Stauss, B. and Mang, P. 1999. Culture shocks in inter-cultural service encounters?. The Journal of Services Marketing 13 (4/5): 329-46.

Tam, J. 2005. Examining the dynamics of consumer expectations in a Chinese context. Journal of Business Research 58(6): 777-786.

Tam, J. 2007. Managing customer expectations in financial services: opportunities and challenges. Journal of Financial Services Marketing 11(4): 281-289. 
Tam, J. 2008. Brand familiarity: its effects on satisfaction evaluations. The Journal of Services Marketing 22(1): 3-12.

Tsiros, M., Mittal, V. and Ross, W. Jr. 2004. The role of attributions in customer satisfaction: an examination. Journal of Consumer Research: 476-483.

Triandis, H. C. 1994. Culture and social behavior. New York, NY: McGraw Hill.

Triandi, H. C. 2006. Cultural intelligence in organizations. Group \& Organization Management 31(1): 20-26.

Tse, D., Nicosia, F. and Wilton, P. 1990. Consumer satisfaction as a process. Psychology \& Marketing 7(3): 177-193.

United Nations (2010). International migration. New York: United Nations Population Division.

Vàzquez-Casielles, R., del Río-Lanza, A. and Díaz-Martín, A. 2007. Quality of past performance: impact on consumers' responses to service failure. Marketing Letters 18: 249-264.

Warden, C. A., Liu, T. C., Huang, C. T. and Lee, C. H. 2003. Service failures away from home: benefits in intercultural service encounters. International Journal of Service Industry Management 14(4): 436-57.

Weiermair, K. 2000. Tourists' perceptions towards and satisfaction with service quality in the cross-cultural service encounter: implications for hospitality and tourism management. Managing Service Quality 10(6): 397-409. 
Weiermair, K. and Fuchs, M. 2000. The impact of cultural distance on perceived service quality gaps: the case of alpine tourism. Journal of Quality Assurance in Hospitality and Tourism 1(2): $59-75$

Weiner, B. 1980. A cognitive (attribution)-emotion-action model of motivated behavior: an analysis of judgments of help-giving. Journal of Personality and Social Psychology 39 (February): 186-200.

Weiner, B. 2000. Attributional thoughts about consumer behavior. Journal of Consumer Research 27 (December): 382-387.

World Tourism Organization 2012. Inbound tourist arrivals. UNWTO World Tourism Barometer.

World Bank 2012. Data catalog.

Zeithaml, V. A., Berry, L. and Parasuraman, A. 1993. The nature and determinants of customer expectations of service. Journal of the Academy of Marketing Science 21(1): 1-12.

Zeithaml, V. A., Bitner, M. and Gremler, D. 2009 Services marketing: integrating customer focus across the firm. McGraw-Hill.

Zhang, J., Beatty, S. and Walsh, G. 2008. Review and future directions of cross-cultural consumer services research. Journal of Business Research 61: 211-224. 
Figure 1 Customer Satisfaction in Intercultural Service Encounters

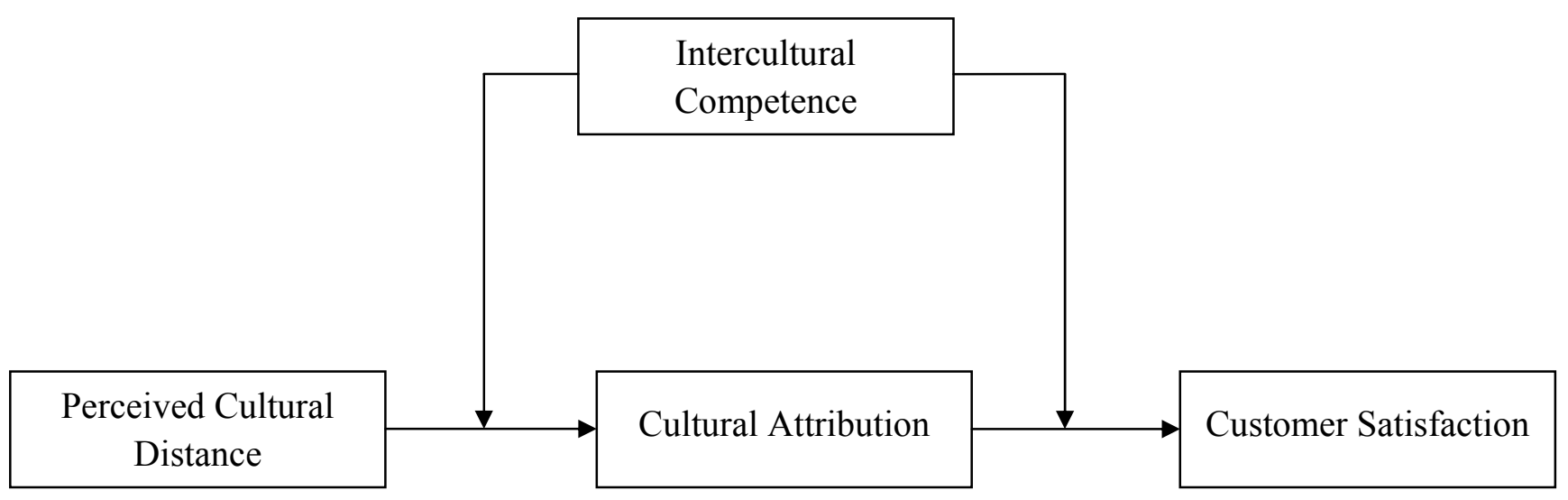


Table 1. Scale Summary

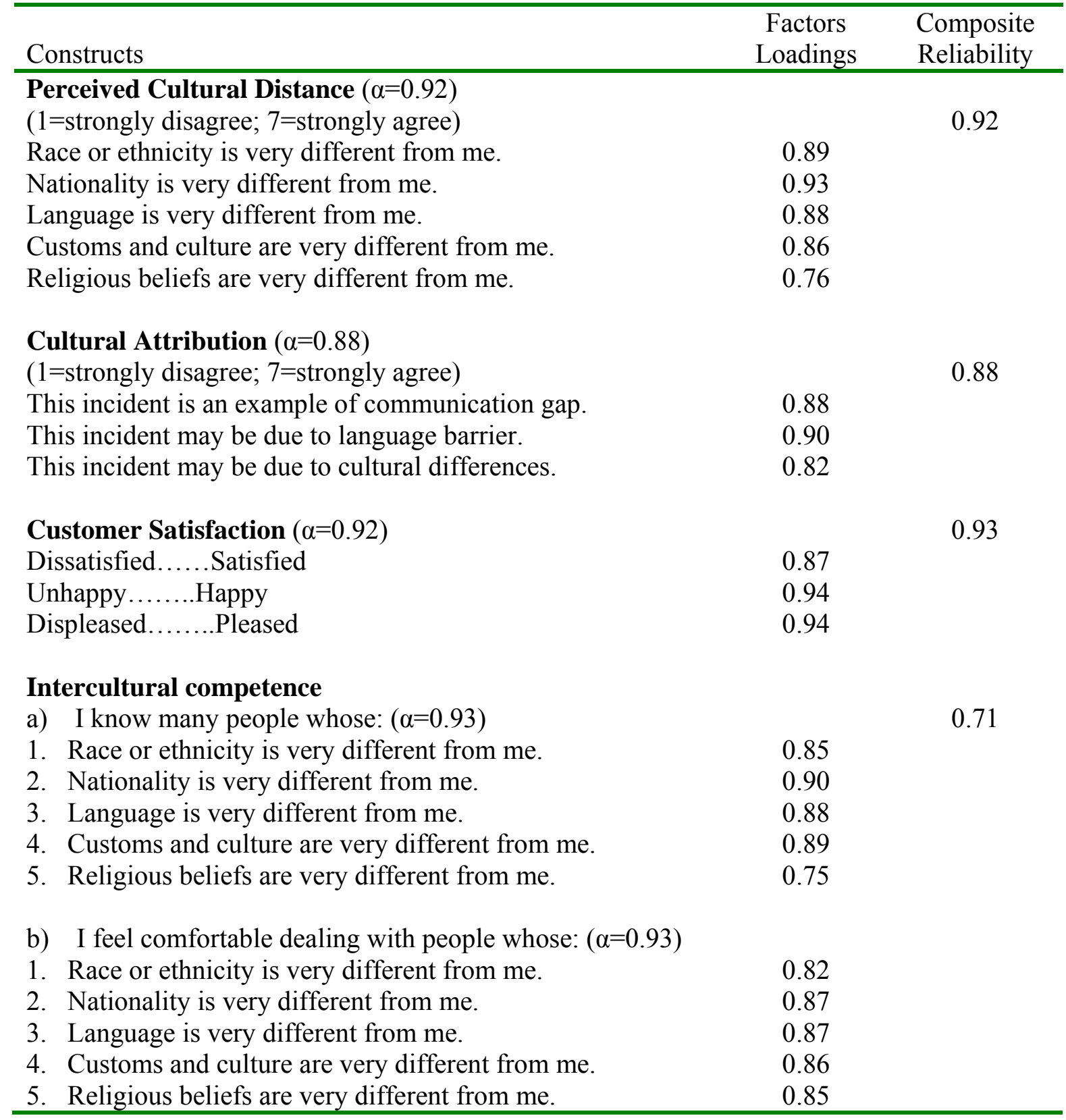


Table 2 Results of the Analysis

\begin{tabular}{|c|c|c|c|c|c|c|}
\hline & \multicolumn{2}{|c|}{ Model $1(\mathrm{DV}=\mathrm{SAT})$} & \multicolumn{2}{|c|}{ Model $2(\mathrm{DV}=\mathrm{CA})$} & \multicolumn{2}{|c|}{ Model 3(DV=SAT) } \\
\hline Predictors & B & $\mathrm{t}$ & $\beta$ & $\mathrm{t}$ & $\beta$ & $\mathrm{t}$ \\
\hline $\begin{array}{l}\text { Perceived cultural distance } \\
\text { (PCD) }\end{array}$ & $\begin{array}{c}0.479 * \\
\left(\beta_{11}\right)\end{array}$ & 3.571 & $\begin{array}{c}0.649 * \\
\left(\beta_{21}\right)\end{array}$ & 3.427 & $\begin{array}{c}0.287^{*} \\
\left(\beta_{31}\right)\end{array}$ & 2.073 \\
\hline $\begin{array}{l}\text { Intercultural competence } \\
\text { (ICC) }\end{array}$ & $\begin{array}{c}0.225^{*} \\
\left(\beta_{12}\right)\end{array}$ & 2.052 & $\begin{array}{r}0.242 \\
\left(\beta_{22}\right)\end{array}$ & 1.562 & $\begin{array}{r}0.258^{*} \\
\left(\beta_{32}\right)\end{array}$ & 2.050 \\
\hline PCDxICC & $\begin{array}{r}-0.086^{*} \\
\left(\beta_{13}\right)\end{array}$ & -2.895 & $\begin{array}{r}-0.090 * \\
\left(\beta_{23}\right)\end{array}$ & -2.125 & $\begin{array}{r}-0.056 \\
\left(\beta_{33}\right)\end{array}$ & -1.856 \\
\hline Cultural Attribution (CA) & & & & & $\begin{array}{c}0.417^{*} \\
\left(\beta_{34}\right)\end{array}$ & 2.397 \\
\hline CAxICC & & & & & $\begin{array}{r}-0.048 \\
\left(\beta_{35}\right)\end{array}$ & -1.221 \\
\hline
\end{tabular}

significantly different from zero at the $5 \%$ level 